\title{
An Examination of Concussion Symptom Base Rates for Children Aged 5-18 Years
}

\author{
Mary Miller ${ }^{1}$ (D) - Janet Leathem ${ }^{1}$
}

Received: 10 May 2016 /Revised: 15 September 2016/Accepted: 26 September 2016/Published online: 11 October 2016

(C) American Academy of Pediatric Neuropsychology 2016

\begin{abstract}
Aim The aim of this research was to establish base rate levels of frequency and severity of concussion symptoms for normally developing New Zealand children aged 5 to 18 years. A further aim was to compare the rates obtained through parental report with a previous study based on the self-report of New Zealand children aged 11-13 years and with studies conducted in the USA also based on parental report.

Method Parents completed an online survey composed of items from the Post-Concussion Symptom Inventory-parental form (PCSI-p) with additional items from Couch and Leathem (2011).

Results Symptoms of "irritability," "frustration," and "impatience" were commonly reported on a daily or weekly basis, and these symptoms plus "sadness," "emotionality," "fatigue," and "disorganisation" were reported at least monthly. The mean severity rating of symptoms was low, with a weak correlation between severity and frequency. Examination of differences in PCSI-p total scores revealed no difference across age bands. Self-report of symptom frequency was significantly higher in the Couch and Leathem study than parental report in the same age group in the current study which were in turn higher than reported by Sady et al. (Archives of Clinical Neuropsychology, 29, 348-363, 2014) and Gioia et al. (Journal of the International Neuropsychological Society, 14(S1), 204, 2008). There were no significant differences found between males and females for total score, although
\end{abstract}

Mary Miller

mary.miller.6@uni.massey.ac.nz

School of Psychology, Massey University, P.O. Box 756, Wellington, New Zealand females scored significantly higher than males for "emotionality."

Conclusions Some symptoms of concussion are reported in normally developing children in the absence of concussion. Differences in methodology affect reported base rates, and hence, when referring to base rates in a clinical setting, attention should be paid to the methodology used.

Keywords Children $\cdot$ Concussion $\cdot$ Mild traumatic brain injury $(\mathrm{mTBI}) \cdot$ Base rates $\cdot$ Post-concussion symptom inventory (PCSI) · New Zealand

Head trauma is a common injury experienced by approximately $1 \%$ of children aged 0 to 14 years over a year period in New Zealand/Aotearoa and is sustained more frequently by boys than girls, rural populations more than urban populations, and by Māori children more than children of European descent (Feigin et al. 2013). Feigin et al. (2013) reported a higher incidence of TBI per 100,000 people (790 cases) than those reported in comparable European countries (4 to 453 cases) and North America (5 to 618 cases).

Most head trauma accompanied by neurological symptoms is termed mild traumatic brain injury (mTBI) or concussion. The resulting physical, cognitive, and emotional symptoms generally resolve quickly (Babikian and Asarnow 2009); however, 3 months post-injury, 9-7 \% of children experience a cluster of on-going symptoms referred to as post-concussive syndrome (PCS; Ayr et al. 2009; Barlow et al. 2010). Determining the true incidence, prevalence, and aetiology of PCS, however, is difficult (Iverson et al. 2010a) especially in children (Iverson and Lange 2011) with PCS-like symptoms also reported by non-clinical populations (Dean et al. 2012) and by those with psychological and other medical issues (Iverson et al. 2010b). Chan (2001) reports 
that brain injury-like symptoms, such as tinnitus, difficulty remembering, and headaches, are common in patients who have not experienced head injury. These findings are similar to previous studies that suggest that headaches, fatigue, anxiety, sleep difficulties, and irritability are also common in the non-clinical population (Lees-Haley and Brown 1993). Questionable specificity of PCS symptoms makes distinguishing these symptoms from base rates for nonclinical populations difficult; it is possible that normally occurring symptoms are subsequently attributed to a brain injury (Dean et al. 2012). The symptoms may be caused by daily stresses or other causes (Chan 2001).

Assessment of the presence and severity of PCS symptoms is typically through interview and completion of self and/or respondent questionnaires. Questionnaires may be subject to bias, however, as endorsing of a list of symptom results in more symptoms being reported than are reported in interviews (Nolin et al. 2006). Further, the presence of symptoms prior to head injury is often under-reported. One way of controlling for false positive results is by setting reported symptoms against base rates, i.e., the rate of specified criteria in the general population (Murphy and Davidshofer 2005).

Four studies have looked at base rates of concussion symptoms reported for children without concussion (healthy controls). Couch and Leathem (2011) used a 38-item selfreport questionnaire adapted for 11 to 13 year olds from Lees-Haley and Brown's (1993) study with adults, while Gioia et al. (2008) and Sady et al. (2014) used parent and self-report versions of the Post-Concussion Symptom Inventory (PCSI; Gioia et al. 2008) with 5 to 18 year olds. PCSI refers to the self-report version of the measure, whereas the PCSI parental form is abbreviated to PCSI-p (Gioia et al. 2008).

Higher levels of symptom base rates were self-reported by 11 to 13 year olds in Couch and Leathem (2011) (similar to levels found by Lees-Haley and Brown (1993) in the self-reports of an adult population) than were reported by parents in Gioia et al. (2008) and Sady et al. (2014) studies. The extent to which the differences between the studies were due to variation in the methods of measurement (self-report versus parental report and single symptoms versus total symptom scores), the populations involved, and/or variation in the time period that respondents were questioned on will be explored in the current study.

Chan (2005) suggests that it is important to record frequency and intensity of symptoms in addition to their presence, as even though healthy controls exhibit PCS symptoms, those with mTBI report a greater number of symptoms and rate them as higher in severity. Grubenhoff et al. (2011) caution, however, that symptoms graded on their severity are inherently more subjective than a dichotomous selection of the presence or absence of a symptom.
Previous research with children (Couch and Leathem 2011; Sady et al. 2014) and with adults by Lees-Haley and Brown (1993) found no significant gender differences in base rates.

\section{Research Aims and Hypotheses}

The current study aimed to establish base rate data for PCStype symptoms in healthy children aged 5 to 18 years in New Zealand and to compare these with previous research by Couch and Leathem (2011), Gioia et al. (2008), and Sady et al. (2014).

It was hypothesized that symptoms rated as severe would be reported less frequently than mild symptoms, that the frequency of symptoms would decrease as reporting periods became shorter, and that the frequency and severity of symptoms reported by parents would be lower than symptoms reported by children. It was also hypothesized that our results using the PCSI-p would be similar to those reported by Gioia et al. (2008) and Sady et al. (2014).

\section{Methodology}

\section{Questionnaire}

An online questionnaire was developed that included the 20 PCSI-p questions and the 35 questions used by Couch and Leathem (2011). Twelve duplicate questions from the Couch and Leathem questionnaire were eliminated, leaving 43 symptom questions. Eight distractor items (symptoms not associated with concussion) used by Couch and Leathem were retained. Where necessary items from the PCSI-p and Couch and Leathem's questionnaire were modified so that the resulting questionnaire had consistent and logical syntax, e.g., Couch and Leathem's item "feel dizzy," the PCSI-p's phrasing "appears or complains of dizziness," in the current study were changed to "have they appeared or complained of dizziness...". The questionnaire included questions regarding the severity of symptoms and the time frame in which symptoms were observed.

Demographic information on age, gender, location, ethnicity, and socioeconomic status (SES) was gathered at the start of the questionnaire, to ensure that the population was representative of the general population. The Australian Socioeconomic Index 2006 (AUSEI06; McMillan et al. 2009) questions on employment were used as an approximation of SES, and for parents not in employment, education level was used as a proxy for SES. The research was approved by Massey University Human Ethics Committee reference 14/56. 


\section{Procedure}

The target school was a co-educational state integrated Steiner school, in Auckland, New Zealand. ${ }^{1}$ It was selected because the school had students across the age range targeted in this research (5 to 18 years). On approval from the school's Board of Trustees, information about the study with a link to an online questionnaire was sent to parents through the school's email system. Parents were asked to forward it on to other parents who might also wish to participate. Accordingly, while it is likely that most of the participants came from that school, some could have come from elsewhere. No incentive was offered to parents for completing the questionnaire, other than the explanation that the information gathered in the research would be helpful in the treatment of childhood concussion. Factors that may have influenced parents to respond besides a wish to contribute to research included having the time to answer the questionnaire and access to a computer. Complaints or symptom endorsements by parents of their children's symptoms were taken at face value and not evaluated on whether symptoms were observed or not. The questionnaire was hosted on the secure Qualtrics survey system. Power calculated using G Power, with effect size d of 0.5 (medium size), alpha error 0.05 , and power 0.95 , indicated that the total number of participants required was 220 .

\section{Participants}

Parents were excluded if they were not currently a resident in New Zealand and if their child was still experiencing symptoms of concussion (7 respondents; $2.6 \%)$. Parents who reported that their child had experienced a head injury or concussion at some stage but were not now experiencing symptoms related to this injury were included $(23.6 \% ; n=61$, but only 44 completed the questionnaire).

Of the 272 eligible participants who attempted the questionnaire, 222 completed it although some completers chose not to answer some demographic questions. With a school roll of 645 , this represents a response rate of $42 \%$, although as noted above, this is likely to be inflated due to parents of the target school forwarding on the email. Characteristics of children and parents are shown in Table 1 below and the percentage of participants who answered each question is stated along with the number of participants this represents.

\footnotetext{
${ }^{1}$ State integrated schools in New Zealand must deliver the state education as well as their special character education, in this case Steiner education, which is based on the teachings of Rudolf Steiner.
}

\section{Results}

\section{Frequency}

Table 2 shows the percentage frequencies (daily, weekly, and monthly) of concussion symptoms. Symptoms occurring at least weekly (daily and weekly combined) were "irritable" (45.7\%), "impatient" (45.7\%), "frustrated" (45.1\%), "emotional" (39.3\%), and "disorganized" (39.1\%).

Total positive symptom scores were calculated from the sum of monthly, weekly, or daily scores (participants were only able to select one of these categories; so, their answer would not be counted multiple times), meaning these children were reported by parents to experience that symptom at least once a month. The total positive symptom score resulted in seven symptoms being reported by more than half of the participants, "frustrated"-66\%; "irritable"-65.1\%; "sad"$62.6 \%$; "emotional"- $60.7 \%$; “impatience"-57.6\%; "fatigued" $-52.2 \%$; and "disorganized" $-50.7 \%$. Asking respondents to report symptoms experienced at least once a month (total positive symptom frequency) produced significantly higher rates than over the previous $24 \mathrm{~h}(U=709.50$, $p<0.05, r=-0.20$ ). Distractor items (symptoms not associated with $\mathrm{mTBI} /$ concussion) tended to be at the lower end of reported total positive symptom scores. The results were examined to investigate a potential confound between the symptoms reported by parents who stated their child had previously experienced concussion but who were not currently experiencing related symptoms $(n=44)$, and those children who had never experienced a concussion $(n=168)$. There was no significant difference found between these two groups ( $U=888.50$, ns, $r=0.38)$.

\section{Severity}

Table 2 also shows the mean severity ratings related to each symptom. Severity was measured on a scale of 0 to $6(0=$ no problem, $6=$ severe problem). The mean severity rating across all symptoms (calculated for only those children who were rated as having a problem, i.e., rated 1-6, $N=$ ) was 1.79. Analysis showed that there was a weak correlation between frequency and severity, $r=.335, p<0.05$. For example, the symptom with the highest severity rating "noise" (2.32) was reported by only $21.4 \%$ of parents, compared to the most frequently reported symptom "frustrated," (2.08) reported by $66.0 \%$ of parents.

\section{Age Bands}

The PCSI-p uses age bands for data analysis of base rate differences, i.e., 5 to 7,8 to 12 , and 13 to 18 years, and the total positive symptom scores (symptoms reported at least monthly) for each these age bands are also shown in 
Table 1 Demographic variables

\begin{tabular}{|c|c|c|c|c|c|}
\hline \multicolumn{3}{|l|}{ Children } & \multicolumn{3}{|l|}{ Parents } \\
\hline \multicolumn{2}{|c|}{$\begin{array}{l}\text { Demographic } \\
\text { variable }\end{array}$} & \multirow{2}{*}{$\begin{array}{l}\text { Percentage } \\
(n)\end{array}$} & \multicolumn{2}{|c|}{ Demographic variable } & \multirow{2}{*}{$\begin{array}{l}\text { Percentage }(n) \\
8.5(17)\end{array}$} \\
\hline Age & 5 & & Employment & Clerical/Administrative & \\
\hline & 6 & $8.3(21)$ & & $\begin{array}{l}\text { Community/Personal } \\
\text { service }\end{array}$ & $14.6(29)$ \\
\hline & 7 & $11.4(29)$ & & Manager & $10.1(20)$ \\
\hline & 8 & $9.4(24)$ & & Professional & $57.8(115)$ \\
\hline & 9 & $12.6(32)$ & & Sales work & $5.5(11)$ \\
\hline & 10 & $6.7(17)$ & & Technical/Trade & $3.5(7)$ \\
\hline & 11 & $8.3(21)$ & & Labourer & $0.0(0)$ \\
\hline & 12 & $5.9(15)$ & & Machinery driver/operator & $0.0(0)$ \\
\hline & 13 & $6.7(17)$ & & Not employed & $10.4(23)$ \\
\hline & 14 & $4.7(12)$ & $\begin{array}{l}\text { Highest } \\
\text { education }\end{array}$ & Left school before year 9 & $0.0(0)$ \\
\hline & 15 & $4.3(11)$ & & Completed year 9 & $0.0(0)$ \\
\hline & 16 & $5.5(14)$ & & Completed year 10 & $0.0(0)$ \\
\hline & 17 & $3.5(9)$ & & Completed year 11 & $0.0(0)$ \\
\hline & 18 & $1.6(4)$ & & Completed year 12 & $9.8(5)$ \\
\hline \multirow[t]{2}{*}{ Gender } & Male & $53.1(135)$ & & Post-school diploma & $29.4(15)$ \\
\hline & Female & 46.9 (119) & & $\begin{array}{l}\text { Post-school degree } \\
\text { or higher }\end{array}$ & $60.8(31)$ \\
\hline \multirow[t]{6}{*}{ Ethnicity } & NZ European & $79.1(200)$ & & & \\
\hline & Other European & $6.3(16)$ & & & \\
\hline & Māori & $5.9(15)$ & & & \\
\hline & Pacific peoples & $1.2(3)$ & & & \\
\hline & Asian & $4.4(11)$ & & & \\
\hline & Other & $3.2(8)$ & & & \\
\hline \multirow[t]{2}{*}{ Location } & Urban & $86.9(219)$ & & & \\
\hline & Rural & $13.1(33)$ & & & \\
\hline
\end{tabular}

Table 2. There was no significant difference found between the age bands for total positive symptom frequency using the Kruskal-Wallis test, $H(2)=0.330, p=0.848$. The most commonly reported symptom "frustration" was examined using the Mann-Whitney $U$ test for the lowest age band (5 to 7 years) and the highest age band (13-18 years), and a significant difference was found ( $U=1270.50, p<0.05, r=-0.28)$. Symptoms reported in the different age bands for the PCSI-p total score showed no significant difference $(H(2)=0.259$, $p=0.879)$. Comparison of the lowest band $(M d n=3)$ with the highest band $(M d n=3)$ revealed no significant difference on the PCSI-p total symptom scores $(U=1679.00$, ns, $r=-0.03)$.

\section{Parent Versus Self-report}

Table 3 shows the results of parents' reports for 11 to 13 years old in the current study compared to the self-report of 11 to 13 years old reported by Couch and Leathem (2011). Comparison of total positive symptom scores for symptoms experienced at least monthly using the Mann-Whitney $U$ test showed that there was a significant difference between the studies $(M d n=29.5), U=355, p<0.01, r=-0.36$. The Couch and Leathem results were higher due predominantly to higher endorsement by children across all symptoms (including distractor items), whereas parents clearly endorse some but not all symptoms. No significant different differences were seen between the top 10 symptoms in the present study using parental report compared to Couch and Leathem using self-report by children.

\section{Comparison of the current study with US studies}

The PCSI-p includes a rating scale of 0 (no symptom) to 6 (severe symptom), and hence, parents rate both presence and severity of symptoms in one item. As shown in Table 4, parents in the current study reported more symptoms during the past $24 \mathrm{~h}$ than in the Sady et al. (2014) study over the same period, i.e., parents in the United States (US) were more likely to say (mean $95.1 \%$ ) that their child had no problem of any 
Table 2 Concussion symptom frequency (monthly, weekly, daily, past $24 \mathrm{~h}$ ) and severity for total sample, males, and females

\begin{tabular}{|c|c|c|c|c|c|c|c|c|c|c|c|}
\hline \multirow[t]{3}{*}{ Symptoms } & \multirow{3}{*}{$\mathrm{n}$} & \multicolumn{3}{|c|}{ Frequency } & \multicolumn{6}{|c|}{ Total positive symptoms } & \multirow[t]{3}{*}{ Severity (n) } \\
\hline & & \multirow{2}{*}{$\begin{array}{l}\text { Monthly } \\
\%(n)\end{array}$} & \multirow{2}{*}{$\begin{array}{l}\text { Weekly } \\
\%(n)\end{array}$} & \multirow{2}{*}{$\begin{array}{l}\% \text { Daily } \\
(n)\end{array}$} & \multirow[t]{2}{*}{ Total } & \multicolumn{3}{|c|}{ Age bands (years) } & \multicolumn{2}{|l|}{ Gender } & \\
\hline & & & & & & $\begin{array}{l}5-7 \\
(n)\end{array}$ & $\begin{array}{l}8-12 \\
(n)\end{array}$ & $\begin{array}{l}13-18 \\
(n)\end{array}$ & $\begin{array}{l}\text { Female } \\
(n=104)\end{array}$ & $\begin{array}{l}\text { Male } \\
(n=111)\end{array}$ & \\
\hline Frustrated & 215 & $16.3(45)$ & $28.8(62)$ & $16.3(35)$ & $66.0(142)$ & $76.8(53)$ & $67.4(64)$ & $49.0(25)$ & 67.3 & 64.9 & $2.08(146)$ \\
\hline Irritable & 232 & $19.4(45)$ & $27.6(64)$ & $18.1(42)$ & $65.1(151)$ & $65.2(45)$ & $73.7(70)$ & $52.9(27)$ & 74.0 & 58.6 & $1.93(154)$ \\
\hline Sad & 230 & $29.1(67)$ & $27.0(62)$ & $6.5(15)$ & $62.6(144)$ & $71.0(49)$ & $67.4(64)$ & $49.0(25)$ & 69.2 & 59.5 & $1.76(146)$ \\
\hline Emotional & 229 & $21.4(49)$ & $28.4(65)$ & $10.9(25)$ & $60.7(139)$ & $69.6(48)$ & $21.1(59)$ & $51.0(26)$ & 76.0 & 48.6 & $1.94(142)$ \\
\hline Impatient & 217 & $12.9(28)$ & $31.3(68)$ & $13.4(29)$ & $57.6(125)$ & $71.0(49)$ & $55.8(53)$ & $45.1(23)$ & 68.3 & 48.6 & $1.92(126)$ \\
\hline Fatigued & 224 & $24.6(55)$ & $23.2(52)$ & $4.5(10)$ & $52.2(74)$ & $53.6(37)$ & $53.7(51)$ & $47.1(24)$ & 60.6 & 44.1 & 1.75 (119) \\
\hline Disorganised & 215 & $11.6(25)$ & $22.8(49)$ & $16.3(35)$ & 50.7 (109) & $36.2(25)$ & $59.6(56)$ & $54.9(28)$ & 49.0 & 52.7 & $2.00(112)$ \\
\hline Concentration & 223 & $12.1(27)$ & $19.7(44)$ & $12.1(27)$ & $43.9(98)$ & $33.8(23)$ & $45.3(43)$ & $51.0(26)$ & 42.3 & 43.6 & $2.21(103)$ \\
\hline Restlessness & 217 & $13.8(30)$ & $18.0(39)$ & $10.6(23)$ & $42.4(92)$ & $36.2(36)$ & $59.6(41)$ & $54.9(15)$ & 43.3 & 42.3 & $1.75(94)$ \\
\hline Trouble sleeping & 215 & $15.3(33)$ & $16.3(35)$ & $8.4(18)$ & $40.0(56)$ & $42.0(29)$ & $41.1(39)$ & $35.5(18)$ & 43.3 & 36.9 & $2.27(88)$ \\
\hline Nervousness & 230 & $21.7(50)$ & $13.5(31)$ & $4.3(10)$ & $39.6(91)$ & $49.3(34)$ & $38.9(37)$ & $31.4(16)$ & 45.2 & 36.0 & $2.05(92)$ \\
\hline Fights & 215 & $12.1(26)$ & $11.6(25)$ & $6.0(13)$ & $29.8(64)$ & $30.4(21)$ & $37.9(36)$ & $13.7(7)$ & 30.8 & 28.8 & $1.59(67)$ \\
\hline Headaches & 240 & $20.4(49)$ & $8.3(20)$ & $0.4(1)$ & $29.2(70)$ & $23.2(16)$ & $31.9(30)$ & $31.4(18)$ & 30.8 & 27.3 & $2.23(74)$ \\
\hline Worried about health ${ }^{\wedge}$ & 217 & $20.3(44)$ & $5.5(12)$ & $1.8(4)$ & $27.6(83)$ & $26.1(18)$ & $28.4(27)$ & $29.4(15)$ & 28.8 & 27.0 & $1.81(60)$ \\
\hline Remembering & 224 & $6.3(14)$ & $9.8(22)$ & $6.7(15)$ & $22.8(51)$ & $13.0(9)$ & $27.4(26)$ & $25.5(13)$ & 24.0 & 20.7 & $1.94(54)$ \\
\hline Slept more & 236 & $16.5(39)$ & $5.1(12)$ & $0.8(2)$ & $22.5(53)$ & $18.8(13)$ & $25.5(24)$ & $23.5(12)$ & 23.1 & 22.7 & $1.47(57)$ \\
\hline Noise sensitivity & 234 & $9.8(23)$ & $7.7(18)$ & $3.8(9)$ & $21.4(50)$ & $31.9(22)$ & $18.9(18)$ & $13.7(7)$ & 26.0 & 18.0 & $2.32(53)$ \\
\hline Nausea & 239 & $14.6(35)$ & $4.2(10)$ & $1.3(3)$ & $20.1(48)$ & $21.7(15)$ & $17.0(16)$ & $23.5(12)$ & 25.0 & 15.5 & $2.07(48)$ \\
\hline Clumsy & 221 & $8.1(18)$ & $8.6(19)$ & $2.7(6)$ & $19.5(42)$ & $17.4(12)$ & $24.2(23)$ & $15.7(8)$ & 22.1 & 18.0 & $1.74(44)$ \\
\hline Lack of interest & 215 & $9.8(21)$ & $8.8(19)$ & $0.9(2)$ & $19.5(42)$ & $14.5(10)$ & $18.9(18)$ & $27.5(14)$ & 20.2 & 18.9 & $1.76(44)$ \\
\hline Confused with tasks & 221 & $9.5(21)$ & $6.8(15)$ & $2.7(6)$ & $19.0(42)$ & $14.5(10)$ & $23.2(22)$ & $19.6(10)$ & 20.2 & 18.9 & $1.64(44)$ \\
\hline Drowsy & 235 & $10.2(24)$ & $6.8(16)$ & $0.9(2)$ & $17.9(42)$ & $53.6(37)$ & $53.7(51)$ & $47.1(24)$ & 19.2 & 16.2 & $1.63(44)$ \\
\hline Everyday tasks & 215 & $3.7(8)$ & $8.4(18)$ & $4.7(10)$ & $16.7(36)$ & $11.6(8)$ & $18.9(18)$ & $19.6(10)$ & 17.3 & 16.2 & $1.67(38)$ \\
\hline Foggy & 229 & $5.7(13)$ & $7.9(18)$ & $3.1(7)$ & $16.6(38)$ & $8.7(6)$ & $21.1(20)$ & $19.6(10)$ & 22.1 & 11.7 & $1.83(42)$ \\
\hline Foot pain ${ }^{\wedge}$ & 215 & $11.6(25)$ & $1.9(4)$ & $1.4(3)$ & $14.9(32)$ & $10.1(7)$ & $17.9(17)$ & $15.7(8)$ & 12.5 & 17.1 & $2.16(33)$ \\
\hline Finding words & 215 & $6.5(14)$ & $6.0(13)$ & $0.9(2)$ & $13.5(29)$ & $20.3(14)$ & $8.4(8)$ & $13.7(7)$ & 12.5 & 14.4 & $1.43(29)$ \\
\hline Hearing & 215 & $8.4(18)$ & $7.0(15)$ & $3.3(7)$ & $13.5(40)$ & 15.9 (11) & $23.2(22)$ & $13.7(7)$ & 20.2 & 17.1 & $1.88(41)$ \\
\hline Back pain ${ }^{\wedge}$ & 219 & $8.3(18)$ & $3.7(8)$ & $0.5(1)$ & $12.4(16)$ & $5.9(4)$ & $14.7(14)$ & $18.0(9)$ & 12.5 & 12.8 & $2.04(29)$ \\
\hline Neck pain $^{\wedge}$ & 217 & $9.7(22)$ & $2.3(5)$ & $0.0(0)$ & $12.0(27)$ & $14.5(10)$ & $11.6(11)$ & $9.8(5)$ & 8.7 & 15.3 & $1.84(26)$ \\
\hline Reading & 215 & $2.3(5)$ & $3.7(8)$ & $4.2(9)$ & $10.2(19)$ & $11.6(8)$ & $12.6(12)$ & $3.9(2)$ & 10.6 & 9.9 & $2.24(22)$ \\
\hline Light sensitivity & 234 & $5.1(12)$ & $3.4(8)$ & $0.4(1)$ & $9.0(21)$ & $5.8(4)$ & $8.4(8)$ & $13.7(7)$ & 6.7 & 10.8 & $2.00(22)$ \\
\hline Dizziness & 237 & $6.8(16)$ & $1.7(4)$ & $0.0(0)$ & $8.4(20)$ & $2.9(2)$ & $7.4(7)$ & $15.7(8)$ & 9.6 & 6.4 & $2.25(20)$ \\
\hline Answering questions & 220 & $2.3(5)$ & $4.1(9)$ & $1.4(3)$ & 7.7 (17) & $7.2(5)$ & $6.3(6)$ & $11.8(6)$ & 7.7 & 8.1 & $1.29(18)$ \\
\hline Speech & 215 & $2.3(5)$ & $4.2(9)$ & $0.9(2)$ & $7.4(16)$ & $13.0(21)$ & $5.3(5)$ & $3.9(2)$ & 7.7 & 7.2 & $1.53(15)$ \\
\hline Visual & 224 & $5.4(12)$ & $1.8(4)$ & $0.0(0)$ & $7.1(16)$ & $5.8(4)$ & $7.4(7)$ & $7.8(4)$ & 8.7 & 5.4 & $2.13(16)$ \\
\hline Balance & 238 & $3.4(8)$ & $0.4(1)$ & $0.0(0)$ & $3.8(9)$ & $1.4(1)$ & $5.3(5)$ & $3.9(2)$ & 5.8 & 1.8 & $2.00(11)$ \\
\hline Trembling & 219 & $2.7(6)$ & $0.5(1)$ & $0.0(0)$ & $3.2(7)$ & $4.3(3)$ & $2.1(2)$ & $3.9(2)$ & 5.8 & 0.9 & $1.14(7)$ \\
\hline Shoulder pain ${ }^{\wedge}$ & 215 & $0.9(2)$ & $0.5(1)$ & $0.5(1)$ & $1.9(4)$ & $1.4(1)$ & $3.2(3)$ & $0.0(0)$ & 1.9 & 1.8 & $2.00(4)$ \\
\hline Bleeding $\wedge$ & 215 & $1.4(3)$ & $0.5(1)$ & $0.0(0)$ & $1.9(4)$ & $0.0(0)$ & $3.2(3)$ & $2.0(1)$ & 1.9 & 1.8 & $1.25(4)$ \\
\hline Pain in elbow ${ }^{\wedge}$ & 219 & $1.8(4)$ & $0.0(0)$ & $0.0(0)$ & $1.8(4)$ & $1.4(1)$ & $3.2(3)$ & $0.0(0)$ & 0.9 & 2.7 & $1.00(4)$ \\
\hline Broken bones $^{\wedge}$ & 219 & $0.5(1)$ & $0.0(0)$ & $0.5(1)$ & $0.9(2)$ & $2.9(2)$ & $0.0(0)$ & $0.0(0)$ & 1.9 & 0.0 & $2.00(2)$ \\
\hline Numbness & 215 & $0.9(2)$ & $0.0(0)$ & $0.0(0)$ & $0.9(2)$ & $1.4(1)$ & $0.0(0)$ & $2.0(1)$ & 0.0 & 1.8 & $1.50(2)$ \\
\hline Seizures & 215 & $0.0(0)$ & $0.0(0)$ & $0.0(0)$ & $0.0(0)$ & $0.0(0)$ & $0.0(0)$ & $0.0(0)$ & 0.0 & 0.0 & $0.00(0)$ \\
\hline
\end{tabular}

Note $^{\wedge}=$ distractor items. Numbers in brackets indicate the number of participants. Daily indicates that the symptom is experienced on average everyday. Past $24 \mathrm{~h}$ indicates that the symptom was experienced in the previous $24 \mathrm{~h}$, but does not specify how frequently the symptom is experienced. Questions for each symptom questions have been abbreviated for clarity in all tables. The number of participants in different age bands varied depending on the number of responses for each symptom who had also completed the demographic questions. The number of participants for gender was $n=215$ ( 222 participants minus those children who were still experiencing symptoms related to a head injury and those who did not complete the gender demographic question). Severity relates to severity for those children whose parents rated them as having some difficulty.

severity over all symptoms than parents in New Zealand (NZ) (mean $77.4 \%$ ). NZ parents were more likely to rate difficulty with symptoms of "irritability," "emotion," "concentration," "sadness," "fatigue," and "remembering", than US parents.

The total symptom severity score for a child on the PCSI-p is calculated by adding together the scores for each of the 20
PCSI-p questions. The total possible score is 120 (i.e., if every symptom was endorsed as severe), and it is the total PCSI-p score that is recommended by the developers to be used in clinical practice, although clinicians may prefer to use individual items. In previous research, Gioia et al. (2008) reported a mean total symptom severity score of $2.2(\mathrm{SD}=4.8)$ on the 
Table 3 Total positive symptom frequencies for 11 to 13 years old compared to previous research by Couch and Leathem (2011)

\begin{tabular}{|c|c|c|c|c|c|}
\hline \multirow[t]{2}{*}{ Symptoms } & \multicolumn{2}{|c|}{ This study } & \multicolumn{3}{|c|}{$\begin{array}{l}\text { Couch and } \\
\text { Leathem (2011) }\end{array}$} \\
\hline & $N$ & monthly \% (n) & $n$ & monthly \% & yearly $\%$ \\
\hline Frustrated & 48 & $54.2(26)$ & 97 & 41.4 & 74.0 \\
\hline Irritable & 47 & $51.1(24)$ & 97 & 55.7 & 79.4 \\
\hline $\mathrm{Sad}$ & 43 & $48.8(21)$ & 97 & 43.3 & 70.1 \\
\hline Impatience & 47 & $44.7(21)$ & 97 & 33.0 & 62.9 \\
\hline Fatigued & 45 & $44.4(20)$ & 97 & 49.5 & 72.2 \\
\hline Disorganised & 43 & $44.2(19)$ & 97 & 38.5 & 63.5 \\
\hline Concentration & 51 & $37.3(19)$ & 97 & 37.5 & 60.4 \\
\hline Restlessness & 43 & $32.6(14)$ & 97 & 39.7 & 52.1 \\
\hline Trouble sleeping & 45 & $31.1(14)$ & 97 & 39.6 & 65.6 \\
\hline Nervousness & 43 & $27.9(12)$ & 97 & 45.9 & 70.8 \\
\hline Fights & 47 & $25.5(12)$ & 97 & 16.6 & 43.7 \\
\hline Headaches & 43 & $20.9(4)$ & 97 & 43.3 & 68.0 \\
\hline Worried about health ${ }^{\wedge}$ & 51 & $19.6(10)$ & 97 & 26.8 & 44.3 \\
\hline Remembering & 43 & $18.6(8)$ & 97 & 34.3 & 49.0 \\
\hline Nausea & 45 & $17.8(8)$ & 97 & 29.5 & 64.2 \\
\hline Lack of interest & 43 & $16.3(7)$ & 97 & 19.8 & 36.5 \\
\hline Confused with tasks & 50 & $16.0(8)$ & 97 & 37.4 & 60.4 \\
\hline Everyday tasks & 50 & $14.0(7)$ & 97 & 26.0 & 43.7 \\
\hline Foot pain $\wedge$ & 44 & $13.6(6)$ & 97 & 37.5 & 56.2 \\
\hline Finding words & 44 & $13.6(6)$ & 97 & 38.6 & 64.6 \\
\hline Hearing & 43 & $11.6(5)$ & 97 & 33.3 & 55.2 \\
\hline Back pain ${ }^{\wedge}$ & 43 & $11.4(5)$ & 97 & 27.8 & 49.5 \\
\hline Neck pain ${ }^{\wedge}$ & 47 & $10.6(5)$ & 97 & 29.9 & 52.6 \\
\hline Reading & 43 & $9.3(4)$ & 97 & 22.9 & 34.4 \\
\hline Dizziness & 50 & $6.0(3)$ & 97 & 24.9 & 47.9 \\
\hline Speech & 43 & $4.7(2)$ & 97 & 20.6 & 47.4 \\
\hline Visual & 50 & $4.0(2)$ & 97 & 15.8 & 29.5 \\
\hline Balance & 43 & $2.3(1)$ & 97 & 24.0 & 36.5 \\
\hline Trembling & 43 & $2.3(1)$ & 97 & 12.3 & 21.6 \\
\hline Shoulder pain ${ }^{\wedge}$ & 43 & $2.3(1)$ & 97 & 19.8 & 38.5 \\
\hline Bleeding $\wedge$ & 43 & $0.0(0)$ & 97 & 16.7 & 42.7 \\
\hline Pain in elbow ${ }^{\wedge}$ & 43 & $0.0(0)$ & 97 & 14.6 & 20.6 \\
\hline Broken bones $^{\wedge}$ & 43 & $0.0(0)$ & 97 & 10.5 & 17.2 \\
\hline Numbness & 43 & $0.0(0)$ & 97 & 13.6 & 28.1 \\
\hline Seizures & 43 & $0.0(0)$ & 97 & 4.1 & 8.3 \\
\hline
\end{tabular}

Note. ${ }^{\wedge}=$ Distractor items

PCSI-p which is considerably lower than obtained in the current study $=6.3(\mathrm{SD}=9.2$ range $0-69)$.

In contrast, Sady et al. (2014) report the mean severity for each symptom on the PCSI-p rather than the total symptom severity score. As is also seen on Table 4, comparison between the Sady et al. results for "Today and Yesterday" compared to the last $24 \mathrm{~h}$ in the current study (calculated by adding the total score $0-6$ divided by the number of participants for each symptom) again reveals significantly higher levels of reporting in terms of severity by NZ parents than US parents (Mann-Whitney $U$ test $M d n=29.5$ ), $U=355, p<0.01$, $r=-0.36)$.

\section{Gender}

Results for males and females are also reported in Table 2. Analysis by Mann-Whitney $U$ test showed that there was no significant group difference on the PCSI-p for total positive symptom frequencies, $U=809.50, n s, r=0.07$ (male $M d n=17.1$; female $M d n=20.2)$ or total symptoms scores, $U=4988.50, n s, r=0.11$ (male $M d n=3$; female $M d n=4$ ). However, reporting group statistics can obscure variation at the individual symptom level and one symptom "emotional" stood out. Mann-Whitney $U$ analysis showed that there was a significant difference in reporting for "emotional" between males and females with a small to medium effect size $\mathrm{U}=4195.50, p<0.01, r=0.28$, with females rated higher.

\section{Discussion}

The current research aimed to establish base rate data for PCStype symptoms in a control group of non-concussed children aged 5 to 18 years in New Zealand and to compare these to previous research by Couch and Leathem (2011), Gioia et al. (2008), and Sady et al. (2014)).

It was hypothesized that symptoms rated as severe would be reported less frequently than mild symptoms, that the frequency of symptoms would decrease as reporting periods became shorter and that the frequency and severity of symptoms reported by parents would be lower than symptoms reported by children. It was also hypothesized that our results using the PCSI-p would be similar to those reported by Gioia et al. (2008) and Sady et al. (2014).

This research shows that many symptoms associated with concussion such as irritability, emotion, concentration, sadness, fatigue, and remembering are commonly experienced as part of normal childhood and that more symptoms are reported over a month, than over shorter periods. Because children experience some of these symptoms on a regular basis, the presence of single symptoms may not provide good discriminatory evidence for the presence of symptoms due to concussion. Failure to consider base rates may lead to false positive diagnoses.

Couch and Leathem (2011) results were recalculated to produce an "at least once a month" category so that results could be compared to the current study. This involved summing their results for the frequency of symptom occurrence for 1 month or less. Comparison with results of the current study with Couch and Leathem (2011) results for 11 to 13 years old revealed a significant difference, due primarily 
Table 4 Percentage for total positive symptom score and mean severity scores of PCSI-p symptoms for current study and Sady et al. (2014)

\begin{tabular}{|c|c|c|c|c|}
\hline \multirow[t]{2}{*}{ Symptoms } & \multicolumn{2}{|c|}{ Current study ${ }^{1}$ (last 24 h) } & \multicolumn{2}{|c|}{ Sady et al. (2014) (today and yesterday) } \\
\hline & Total $\%^{1}$ & $\mathrm{M}(\mathrm{SD})^{2}$ & Total \% & $\mathrm{M}(\mathrm{SD})$ \\
\hline Irritable & 49.1(114) & $0.94(1.24)$ & 22.0 & $0.20(0.62)$ \\
\hline Emotional & $38.0(87)$ & $0.75(1.24)$ & 10.0 & $0.16(0.59)$ \\
\hline Concentration & $30.9(69)$ & $0.61(1.13)$ & 8.0 & $0.15(0.55)$ \\
\hline Sad & $33.9(78)$ & $0.58(1.02)$ & 5.0 & $0.08(0.38)$ \\
\hline Fatigued & $33.0(74)$ & $0.58(1.05)$ & 10.0 & $0.14(0.49)$ \\
\hline Nervousness & $21.7(50)$ & $0.41(0.96)$ & 4.0 & $0.07(0.38)$ \\
\hline Headaches & $41.5(90)$ & $0.36(0.96)$ & 14.0 & $0.30(0.82)$ \\
\hline Remembering & $16.5(37)$ & $0.31(0.88)$ & 6.0 & $0.09(0.41)$ \\
\hline Noise & $14.1(33)$ & $0.27(0.83)$ & 2.0 & $0.04(0.29)$ \\
\hline Nausea & $12.1(29)$ & $0.24(0.76)$ & 1.0 & $0.07(0.39)$ \\
\hline Foggy & $12.7(29)$ & $0.23(0.70)$ & 2.0 & $0.02(0.19)$ \\
\hline Drowsy & $13.2(31)$ & $0.23(0.75)$ & 7.0 & $0.11(0.45)$ \\
\hline Clumsy & $11.8(26)$ & $0.21(0.68)$ & 2.0 & $0.02(0.20)$ \\
\hline Slept more & $17.2(37)$ & $0.20(0.75)$ & 4.0 & $0.07(0.37)$ \\
\hline Confused with tasks & $12.2(26)$ & $0.19(0.58)$ & 3.0 & $0.04(0.27)$ \\
\hline Light & $7.7(18)$ & $0.14(0.64)$ & 3.0 & $0.04(0.32)$ \\
\hline Visual & $5.8(13)$ & $0.09(0.44)$ & 1.0 & $0.03(0.24)$ \\
\hline Dizziness & $5.5(13)$ & $0.08(0.40)$ & 2.0 & $0.03(0.28)$ \\
\hline Answering questions & $4.1(9)$ & $0.06(0.32)$ & 1.0 & $0.01(0.14)$ \\
\hline Balance & $3.8(9)$ & $0.05(0.31)$ & 1.0 & $0.01(0.14)$ \\
\hline
\end{tabular}

1. $\mathrm{N}$ varied for each item

2. Percentage of respondents rating (1 slight problem- 6 severe problem)

3. Mean of scores (0-6) to children endorsing all items, including those rated as occurring infrequently by parents. There was no significant difference between the two studies in the top 10 most commonly reported symptoms. Some symptoms such as "headaches," "worried about health," "remembering," and "confused with tasks" reported more by children than parents may have been because the symptoms are less apparent or obvious to parents than the more observable externalizing symptoms about which there was concordance. This tendency has been previously reported by Murphy et al. (1998).

These results also support the findings of Sady et al. (2014) who found that the self-report of uninjured participants produced a higher endorsement of symptoms than parental report and a moderate concordance $(r=0.44-0.65)$ between parental and self-report versions of the PCSI. Using both methods of data collection would be ideal, but there are practical difficulties in gathering self-report data from young children. Sady et al. (2014) found that the PCSI form for children aged 5 to 7 years was less psychometrically sound than other versions of the form and that interpretation of self-report forms for younger children should be made with caution. They emphasize the usefulness of parental report for the collection of data for young children.
Sady et al. (2014) found that parents of children without concussion were less likely to report symptoms in their children than anticipated, with $63 \%$ of parents reporting on the PCSI-p that their child had no symptoms at all over the $48 \mathrm{~h}$ previously (compared to only $20 \%$ of children themselves reporting no symptoms over that period). By comparison, in the current study, only $16.4 \%$ of parents reported no concussion symptoms at all on the PCSI-p over the past $24 \mathrm{~h}$ (a rate closer to children's self-reporting in Couch and Leathem's (2011) New Zealand study. Sady et al. (2014)) suggest that their lower than expected rate may have been because parents are less aware of symptoms experienced by their children when there is no overt reason, such as illness or injury. The difference could also be due to the different methods of data collection. The New Zealand study was conducted online, whereas the US parents completed the pencil/paper version in a waiting area while their child was undergoing tests as part of a larger study. Which of these two methods has revealed the most accurate true incidence of the base rates in normally developing children remains unclear.

The current study shows that while many symptoms are experienced frequently, they were not necessarily the most severe with only a weak correlation found between severity 
and frequency. Accordingly, as well as enquiring about the frequency of symptoms, as suggested by Chan (2005), the clinician should seek to establish the severity of the symptoms as this may lead to better differentiation of baseline symptoms from symptoms due to post-concussion effects.

Gioia et al. (2008) reported a low total symptom score using the PCSI, which suggests that concussion symptoms are uncommon in a normally developing population, whereas the current study found a considerably higher rate (e.g., that $49.1 \%$ of children without concussion had been irritable in the past $24 \mathrm{~h}$ ). While reporting symptoms over the previous $24 \mathrm{~h}$ may increase the accuracy of reporting, symptoms that are experienced on a fairly regular basis will be missed - this study found that the most frequently endorsed symptoms were experienced weekly.

The PCSI-p items ask about the presence and severity of symptoms experienced. Sady et al. (2014) report base rates for individual symptoms on the PCSI-p, but do not report the total symptom score (which may be used in clinical practice as part of the neuropsychological assessment process). While the presence of any individual symptom response may be considered an indication of possible concussion, further investigation about the possible significance of that symptom is required and an awareness of the base rate may be helpful in that respect. Using a measure with a base rate of less than $15 \%$ may lead to an increase in false negatives (Gouvier et al. 2002). Whether the base rate refers to a total symptom score (one score for entire scale) or an individual symptom should be considered when using base rate data.

\section{Limitations}

Of the 272 participants who attempted the questionnaire, 50 failed to complete it. While there may have been many reasons for non-completion, it is possible that the repetitive question format may not have sustained the participants' interest or even have been irritating.

The research aimed to recruit at least 220 participants in order to achieve sufficient power for statistical analysis. However, because of the number of demographic variables analyzed, it would have been ideal if there were larger numbers of participants in each demographic category. This could be the focus of future research in this area.

\section{Conclusion}

This research reported base rates data for common symptoms related to concussion for children aged 5 to 18 years. Differences in reported base rates in children by Couch and Leathem (2011), Gioia et al. (2008), and Sady et al. (2014) may be explained by the different methodological approaches. Couch and Leathem (2011) explored the frequency of symptoms while Gioia et al. (2008) and Sady et al. (2014) explored the severity of symptoms in the past $24 \mathrm{~h} /$ yesterday and today. Significant differences were found between parental and self-report data, but further research is required in this area. Both forms of report are useful, but there are difficulties with using self-report in young children to establish base rates. Many symptoms were found to be experienced on a regular basis by children, but it should be noted that the severity of these symptoms was low. Gathering data over the previous $24 \mathrm{~h}$ may exclude information, but frequency data from the past year may increase reporting errors. This study supports the view of Chan (2001) who asserted that it was clinically useful to know both the frequency and severity of symptoms. This study provides information about both the frequency and severity of symptoms and produces base rates for individual symptoms as well as the composite scores that the PCSI-p uses. So, from the same data source, base rates can be interpreted as low for the PCSI-p, medium-high for the frequency of some symptoms experienced in the past $24 \mathrm{~h}$, or that symptoms are commonly of minor severity. These differences highlight the need for caution when reporting and interpreting base rate symptoms for clinical use.

\section{Compliance with Ethical Standards}

Conflicts of Interest A conflict of interest was declared to the Massey University Human Ethics committee that the researcher was a School Trustee at the target research site. The research was approved by Massey University Human Ethics Committee reference 14/56. All procedures performed in studies involving human participants were in accordance with the ethical standards of the institutional and/or national research committee and with the 1964 Helsinki declaration and its later amendments or comparable ethical standards. Informed consent was obtained at the beginning of the online questionnaire. No funding source was declared.

\section{References}

Ayr, L. K., Yeates, K. O., Taylor, H. G., \& Browne, M. (2009). Dimensions of postconcussive symptoms in children with mild traumatic brain injuries. Journal of the Interntional Neuropsychological Society, 15(1), 19-30.

Babikian, T., \& Asarnow, R. (2009). Neurocognitive outcomes and recovery after pediatric TBI: meta-analytic review of the literature. Neuropsychology, 23(3), 283.

Barlow, K. M., Crawford, S., Stevenson, A., Sandhu, S. S., Belanger, F., $\&$ Dewey, D. (2010). Epidemiology of postconcussion syndrome in pediatric mild traumatic brain injury. Pediatrics, 126(2), 374-381.

Chan, R. C. (2001). Base rates of post-concussion symptoms among normal people and its neuropsychological correlates. Clinical Rehabilitation, 15(13), 266-273.

Chan, R. C. K. (2005). How severe should symptoms be before someone is said to be suffering from post-concussion syndrome? An exploratory study with self-reported checklist using Rasch analysis. Brain Injury, 19(13), 1117-1124. 
Couch, C. M., \& Leathem, J. M. (2011). An initial study to establish symptom base rates of traumatic brain injury in children. Archives of Clinical Neuropsychology, 26, 349-355.

Dean, P. J., O’Neill, D., \& Sterr, A. (2012). Post-concussion syndrome: prevalence after mild traumatic brain injury in comparison with a sample without head injury. Brain Injury, 26(1), 14-26.

Feigin, V. L., Theadom, A., Barker-Collo, S., Starkey, N. J., McPherson, K., Kahan, M., Dowell, A., Brown, P., Parag, V., Kydd, R., Jones, K., Jones, A., \& Ameratunga, S. (2013). Incidence of traumatic brain injury in New Zealand: a population-based study. Lancet Neurology, 12(1), 53-64.

Gioia, G., Janusz, J., \& Isquith, P. (2008). Psychometric properties of the parent and teacher post-concussion symptom inventory (PCSI) for children and adolescents. Journal of the International Neuropsychological Society, 14(S1), 204.

Gouvier, W. D., Pinkston, J. B., Santa Maria, M. P., \& Cherry, K. E. (2002). Base rate analysis in cross-cultural clinical psychology: Diagnostic accuracy in the balance. In F. R. Ferraro (Ed.), Minority and cross-cultural aspects of neuropsychological assessment. Lisse: Swets \& Zeitlinger B.V.

Grubenhoff, J. A., Kirkwood, M. W., Deakyne, S., \& Wathen, J. (2011). Detailed concussion symptom analysis in a paediatric ED population. Brain Injury, 25(10), 943-949.

Iverson, G. L., \& Lange, R. T. (2011). Post-concussion syndrome. In M. R. Schoenberg \& J. G. Scott (Eds.), The Little Black Book of Neuropsychology (pp. 745-763). New York: Springer.
Iverson, G. L., Brooks, B. L., Ashton, V. L., \& Lange, R. T. (2010a). Interview versus questionnaire symptom reporting in people with the postconcussion syndrome. The Journal of Head Trauma Rehabilitation, 25(1), 23-30.

Iverson, G. L., Lange, R. T., Brooks, B. L., \& Lynn Ashton Rennison, V. (2010b). "Good old days" bias following mild traumatic brain injury. The Clinical Neuropsychologist, 24(1), 17-37.

Lees-Haley, P. R., \& Brown, R. S. (1993). Neuropsychological complaint base rates of 170 personal injury claimants. Archives of Clinical Neuropsychology, 8(3), 203-209.

McMillan, J., Beavis, A., \& Jones, F. L. (2009). The AUSEI06 A new socioeconomic index for Australia. Journal of Sociology, 45(2), $123-149$.

Murphy, K. R., \& Davidshofer, C. O. (2005). Psychological testing: Principles and applications (6th ed.). Upper Saddle River: Pearson Education.

Murphy, L. J., Leathem, J. M., \& Flett, R. A. (1998). Self- and informantratings on the Patient Competency Rating Scale in patients with traumatic brain injury. Journal of Clinical and Experimental Neuropsychology, 5, 694-705.

Nolin, P., Villemure, R., \& Heroux, L. (2006). Determining long-term symptoms following mild traumatic brain injury: method of interview affects self-report. Brain Injury, 20(11), 1147-1154.

Sady, M. D., Vaughan, C. G., \& Gioia, G. A. (2014). Psychometric characteristics of the post-concussion symptom inventory in children and adolescents. Archives of Clinical Neuropsychology, 29, 348-363. 